\title{
Erratum to: Editorial for the Topical Issue “Numerical methods and HPC"
}

Mary Fanett Wheeler ${ }^{1}$, Ani Anciaux-Sedrakian ${ }^{2, *}$, and Quang Huy Tran ${ }^{2}$

${ }^{1}$ Center for Subsurface Modeling, The University of Texas, 201 East 24th Street, ACE 5.324, Campus Mail C0200, Austin, TX 78712, USA

${ }^{2}$ Digital Science and Technology, IFP Energies nouvelles, 1-4, avenue de Bois-Préau, 92852 Rueil-Malmaison Cedex, France

Accepted: 15 July 2019

Oil \& Gas Science and Technology - Revue d'IFP Energies nouvelles 74, E2 (2019)

\section{Line 25}

The original phrase: "The exascale definition limited to machines capable of a rate of 1018 flops is of interest to only few scientific domains."

Must be corrected by: "The exascale definition limited to machines capable of a rate of $10^{18}$ flops is of interest to only few scientific domains."

\footnotetext{
* Corresponding author: ani.anciaux-sedrakian@ifp.fr
} 